\title{
Effect of Hybridization on the Mechanical Properties of Chopped Strand Mat/Pineapple Leaf Fibre Reinforced Polyester Composites
}

\author{
Suhas Yeshwant Nayak, Srinivas Shenoy Heckadka, Nishank Minil Amin, Ramakrishna Vikas Sadanand and Linto \\ George Thomas
}

Department of Mechanical and Manufacturing Engineering, Manipal Institute of Technology, Manipal Academy of Higher Education, Manipal, Karnataka, India-576104

\begin{abstract}
Hybridization of synthetic and natural fibres as reinforcement makes the polymer composites environmental friendly and sustainable when compared to synthetic fibres based polymer composites. In this study chopped strand mat/pineapple leaf fibres were hybridized. Four laminates with six layers each, with different stack sequence (GGGGGG, GPPPPG, PGGGGP and PPPPPP) were fabricated using hand layup technique while maintaining a fibre to matrix ratio of 30:70 by weight with polyester resin as matrix. Mechanical properties such as tensile and flexural strength were determined and morphology of fractured specimens was studied. Maximum tensile strength of $180 \mathrm{MPa}$ was obtained for the laminate with six layers of chopped strand mat followed by hybrid laminate with four layers of chopped strand mat at the centre $(120 \mathrm{MPa})$. Tensile strength of hybrid laminate with four layers of pineapple leaf fibres at the centre was in third position at $86 \mathrm{MPa}$. Least tensile strength of $65 \mathrm{MPa}$ was obtained for the laminate with six layers of pineapple leaf fibres. Similar trend was observed in case of flexural behaviour of the laminates with maximum flexural strength of $255 \mathrm{MPa}$ and minimum flexural strength $107 \mathrm{MPa}$. Scanning electron microscopy of the fractured specimen reinforced with chopped strand mat only, indicated, fibre pull out, matrix cracking and lack of matrix adhesion to fibres. In case of hybrid composite (GPPPPG and PGGGGP) delamination was observed to be prominent due to improper wetting of the pineapple leaf fibres with the matrix. More significant delamination led to lesser strength in case of pineapple fibres reinforced composites even though the fibre pull out was relatively less.
\end{abstract}

\section{Introduction}

With the increased use of polymer composites in our day to day activities comes the need to reduce the cost of manufacturing the polymer composites, thus making it a safer and sustainable material. Polymer Matrix Composite (PMC) generally consist of a reinforcing fibre (natural or synthetic or hybrid) bound together by a polymer based matrix like epoxy, vinyl ester, polyester etc $[1,2]$. The fibres are the basic load bearing member whereas the matrices surrounding the fibres protect the reinforcement and also help in uniform transfer of the loads [3]. Glass fibre in the form of Chopped Strand Mat (CSM) is used as a reinforcing material in many PMCs as they form relatively strong and lightweight composites popularly known as Glass Fibre Reinforced Polymer (GFRP). Although GFRP offer high mechanical strength, they are expensive to fabricate and excess usage of these is not environmental friendly. On the other hand composites made of natural fibres have a much lower cost, they are more sustainable in comparison to synthetic fibres with lower density values $\left(1.5 \mathrm{~g} / \mathrm{cm}^{3}\right.$ vs $\left.2.6 \mathrm{~g} / \mathrm{cm}^{3}\right)$ for pineapple fibres and chopped strand mats respectively $[4,5]$. Two major drawbacks in the selection of natural fibre as reinforcement in composites is that, they offer lower strength in comparison to glass fibres and they are prone to moisture absorption either through direct contact or through the environment leading to swelling and the formation of voids in the polymer composite. Therefore by forming a hybrid composite reinforced by glass and natural fibres it is possible to obtain a product that is both cheaper and easy to use with moderate strength requirements [6]. Higher cellulose content of pineapple fibres make them a good choice for reinforcing material as it offers better mechanical properties [7]. George et al. observed that pineapple/polyethylene composites demonstrated stress relaxation behaviour due to better reinforcement caused by an increase in fibre weight fraction [8]. Chemical treatment of the natural fibres helps to reduce the problems associated with water absorption. Alkali treatment helps in cleaning the surface of the fibres and improves its surface properties for better adhesion with the matrix [9]. Pavithran et al. studied the Pineapple leaf fibre (PALF)/polyester composites with unidirectional orientation of the fibres. They observed that an increase in fibre angle resulted in increased composite toughness [10]. Uma Devi et al. characterized PALF/Polyester composite and studied the effects of coupling agents, fibre loading and fibre length. A linear 
increase in impact, flexural, tensile strengths and Young's modulus was noted when fibre weight fraction was increased. They concluded that the optimum length of fibres was $30 \mathrm{~mm}$ [7]. Mishra et al. tested the mechanical properties of PALF/glass fibre hybrid polyester composites. They found that there was a noticeable improvement in impact, flexural, and tensile strengths of the composites which indicated a positive effect of hybridization through the addition of a small amount of glass fibres [11].

In the present study chopped strand mat and pineapple leaf fibres were hybridized with different stack sequence. Composites were fabricated using hand layup technique. Mechanical characteristics of the composites such as tensile and flexural strength were determined. Scanning electron microscopy was conducted on fractured specimens. This study intends to identify the possibility of using hybrid composites as alternative to synthetic fibre composites in automotive interiors, light loaded furniture and as temporary structural members.

\section{Experimental Details}

\subsection{Materials}

Pineapple fibres were obtained by serrating the pineapple leaves and extracting the fibres using a champ's agro unit. The leaves were procured from local plantations. Fibres were washed, dried and separated according to their diameter by inspecting them visually. They were chopped to $30 \mathrm{~mm}$ in length and soaked in $5 \% \mathrm{NaOH}$ solution for half an hour to remove impurities. This is followed by washing in $1 \% \mathrm{HCl}$ solution and then rinsing with distilled water. Washing with an acid is essential to neutralize effect of any residual alkali [12]. The fibres were then dried for 24 hours at room temperature. Randomly oriented E-glass chopped strand mat (CSM) of $450 \mathrm{gsm}$ was chosen as the synthetic reinforcing material. General purpose polyester resin of density $1.1 \mathrm{~g} / \mathrm{cm}^{3}$ was chosen as the matrix material.

\subsection{Fabrication of composites}

Four laminates of $300 \mathrm{~mm} \times 300 \mathrm{~mm}$ were fabricated using hand layup process with six layers of fabric each, among which two laminates were of hybrid composites. Designation of composites with stacking sequence of plies is presented in Table 1. Fibre weight fraction of $30 \%$ was maintained in all laminates. Composites were cured at room temperature for duration of $24 \mathrm{~h}$. Cured panels are shown in Figure 1.

Table 1: Designation and stacking sequence of composite laminates

\begin{tabular}{|c|c|c|}
\hline Designation & No. of layers & Stacking sequence \\
\hline GFRP & 6 & GGGGGG \\
\hline HYB1 & 6 & PGGGGP \\
\hline
\end{tabular}

\begin{tabular}{|c|c|c|}
\hline HYB2 & 6 & GPPPPG \\
\hline NFRP & 6 & PPPPPP \\
\hline
\end{tabular}

P: Pineapple leaf fibres; G: E-glass CSM
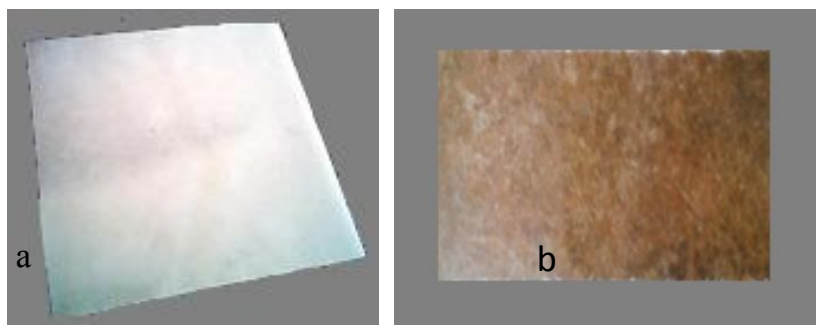

Figure 1. Cured composite panel - (a) GFRP Panel

(b) Hybrid panel

\subsection{Experimental Methods}

Tensile and flexural strengths were determined on the Instron 3366 Universal testing machine having a maximum loading capacity of $10 \mathrm{kN}$. Tensile test specimens of $250 \mathrm{~mm} \times 25 \mathrm{~mm}$ were subjected to a constant cross head speed of $2 \mathrm{~mm} / \mathrm{min}$ as per ASTM D3039 [13].

Flexural testing (ASTM D7264) specimens of $116 \mathrm{~mm}$ x 13mm for GFRP, 154mm x 13mm for HYB1/ HYB2 and $192 \mathrm{~mm} \times 13 \mathrm{~mm}$ for NFRP were subjected to three point bending at a constant cross head speed of $1 \mathrm{~mm} / \mathrm{min}$ [14].

All tests were conducted on conditioned samples at a temperature of $25^{\circ} \mathrm{C}$. Test specimens were cut from the panels using water jet cutting process. The results displayed are the averages of five individual tests. Specimens were visually checked for defects before testing.

Fractured surfaces of the laminates were analysed to understand the probable failure mechanism with the help of a Scanning Electron Microscope (SEM). A thin layer of silver coating was deposited on the specimen surface by ion sputtering and a $15 \mathrm{kV}$ accelerating voltage was used. The SEM was used in variable pressure mode.

\section{Results and Discussions}

\subsection{Mechanical properties of composites}

The comparison of tensile strength of the four laminates is presented in Figure 2. Tensile strength of hybrid laminate HYB1 is lower by $33.3 \%$ and that of HYB2 is lower by $52.2 \%$ while NFRP laminate is even lower at $63.8 \%$ when compared to the tensile strength of GFRP laminate, this can be attributed to fact that pineapple fibres have much lower tensile strength than glass fibres. The possibility of poor interfacial bonding between the layers of the hybrid laminate could be a potential cause as well. 


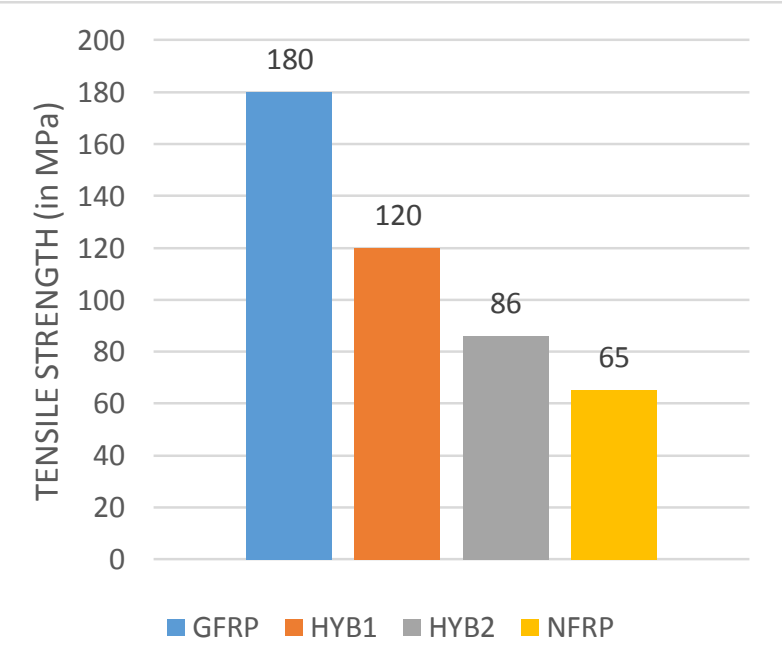

Figure 2. Variation in average tensile strength

From Figure 3 we can understand that the hybrid laminate HYB1 has a lower flexural strength by $24.3 \%$, HYB2 is lower by $50.5 \%$ and NFRP laminate is even more weaker at $58.03 \%$ when compared to flexural strength of the GFRP laminate. Flexural loading subjects specimens to tension on the outermost layers, compression on the innermost layers and delamination in the intermediate layers. All samples in the above case failed due to tension primarily and the results match the values of the tensile test in which GFRP laminate was stronger. As seen in HYB1, higher number of layers of glass fibre led to a higher strength of the laminate whereas in case of laminate HYB2, after the outer layers of glass failed there is a possibility that delamination occurred in the layers of pineapple fibres leading to faster failure at a lower strength value. Since the pineapple fibres have lower tensile strength, the NFRP laminate displayed the weakest flexural strength among all laminates.

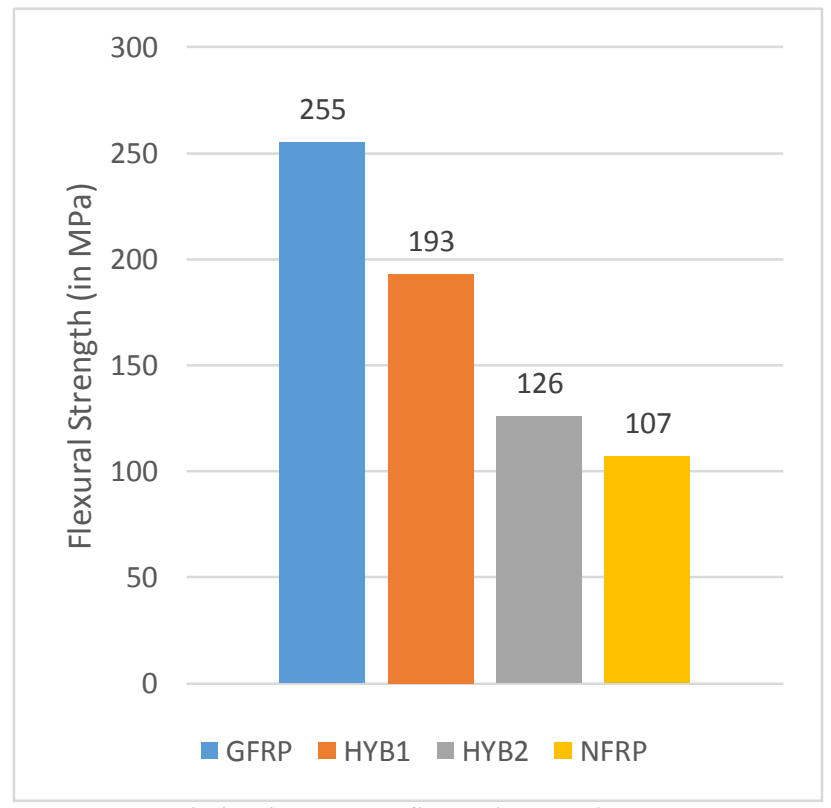

Figure 3. Variation in average flexural strength

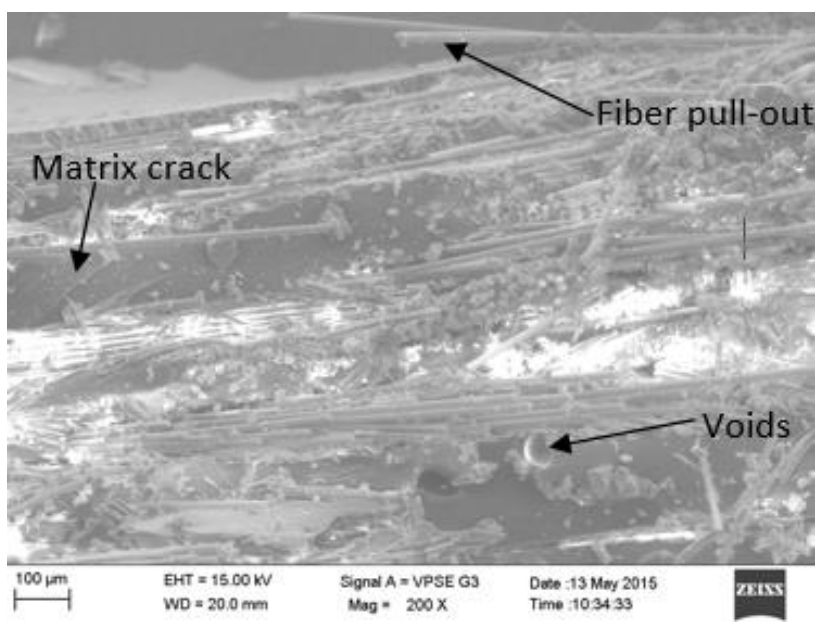

Figure 4. SEM image of GFRP tensile test specimen

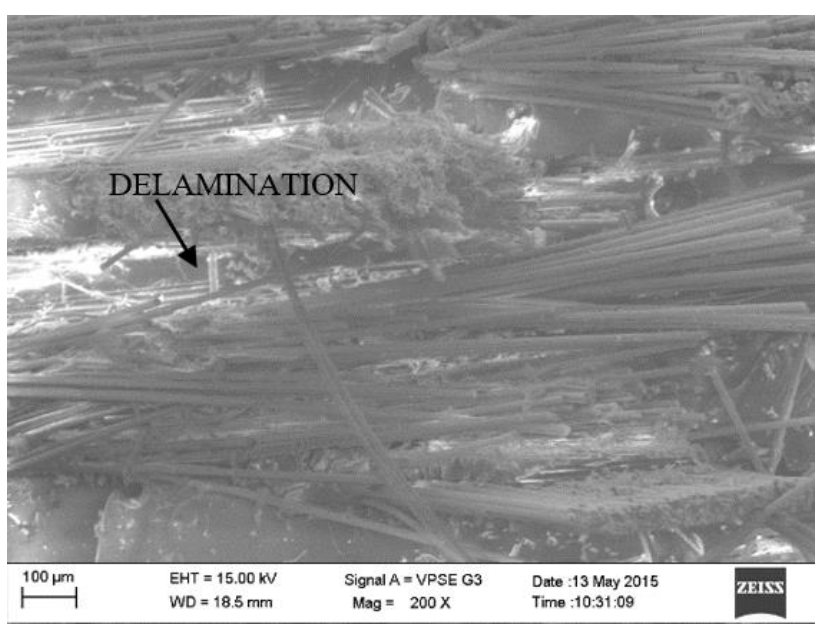

Figure 5. SEM image of GFRP flexural test specimen

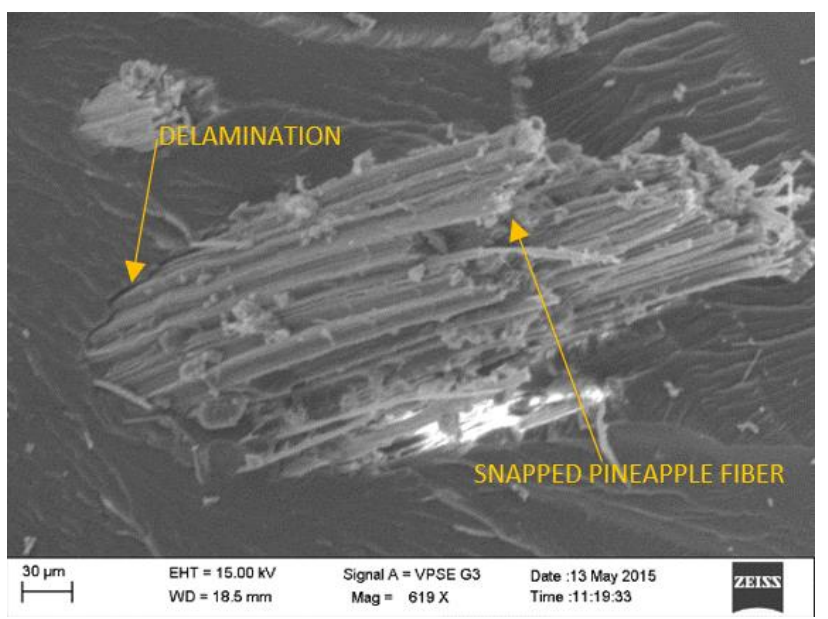

Figure 6. SEM image of NFRP tensile test specimen 


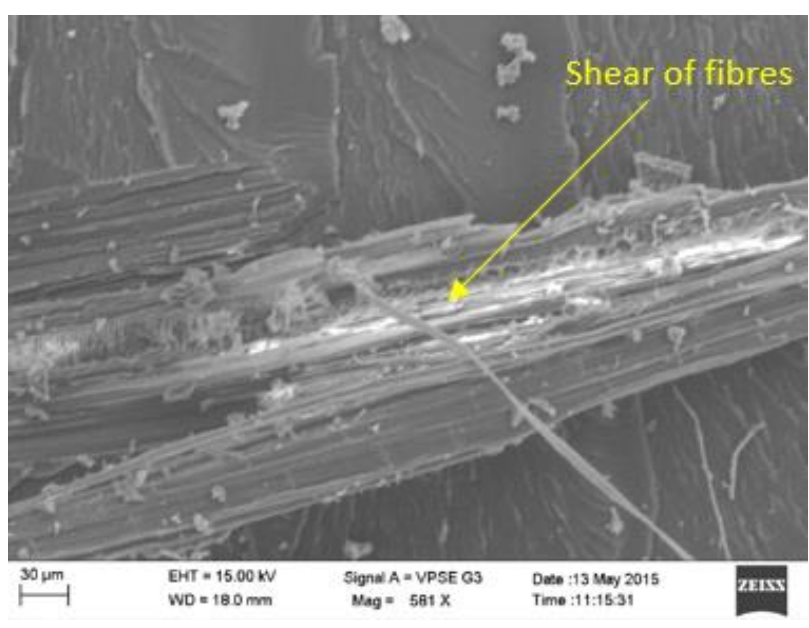

Figure 7. SEM image of NFRP flexural test specimen

\subsection{Morphology of fractured surfaces}

Micrographs of fractured specimens are presented in Figures 4 to 7 . Figure 4 shows the micrograph of GFRP specimen failed through tensile loading. Fibre pull-out is seen at the extremities. Matrix cracking exists between layers of CSM fibres. The presence of voids further contributes to weakening of the laminates. A lack of matrix skin on the fibres displays poor interfacial bonding between fibres and matrix.

Figure 5 shows the micrograph of the GFRP flexural test specimen. A primary failure due to delamination can be observed which was caused by the bending load applied to the specimen. Figure 6 shows the micrograph of NFRP tensile specimen. Delamination can be seen which may be attributed to ineffective treatment of fibres which lead to poor wetting of natural fibres causing poor interfacial bonding with resin. Some fibre pull-out is also visible but it is comparatively lesser than GFRP specimen which is an evidence of lower tensile strength of pineapple leaf fibre. Fibre shearing is evident in the micrograph of NFRP flexural test specimen (Figure 7).

\section{Conclusion}

The GFRP laminate results obtained show an agreement to the generally accepted values of strength for this type of laminate. Hybrid laminates display lower tensile strength in comparison to GFRP but have a relatively decent flexural strength and hence can be used to reduce costs and increase recycling in objects that primarily undergo flexural loading like surfboards, automotive interiors, light loaded furniture and temporary structural members. Laminates having natural fibres closer to the centre of the laminate show lower strength in both loading conditions. The SEM images show delamination, fibre pull out and matrix cracking as modes of failure. Improving the treatment of natural fibres will help in proper wetting of fibres reducing the chances of delamination based failures, hence increasing the strength of hybrid laminates.

\section{Acknowledgements}

The authors are thankful to Dr. K Jagannath, Head of the Department, Mechanical and Manufacturing Engineering for permitting us to make use of the Advanced Material Testing and Research Laboratory. The authors are also indebted to Dr. Satish Shenoy B, Head of the Department and Mr. Padmaraj N. H., Assistant Professor, Department of Aeronautical and Automobile Engineering for allowing us to use their Advanced Composite and Material Testing Laboratory. The authors thank Manipal College of Dental Sciences, Manipal for permitting us to use their material testing facilities. The authors would also like to thank M/s. Konkan Speciality Polyproducts Pvt. Ltd., Mangalore for providing us their testing facility. The authors thank Mr. Anand Moolya for providing the pineapple leaves.

\section{References}

1. Ramnath, B. Vijaya, C. Elanchezhian, P. V. Nirmal, G. Prem Kumar, V. Santhosh Kumar, S. Karthick, S. Rajesh, and K. Suresh. "Experimental investigation of mechanical behavior of jute-flax based glass fibre reinforced composite." Fibre. Polym. 15, 6 (2014): 1251-1262.

2. Mahesha, G. T., S. B. Satish, K. M. Vijaya, and K. Subrahmanya Bhat. "Preparation of unidirectional grewia serrulata fibre-reinforced polyester composites and evaluation of tensile and flexural properties." J. Nat. Fibres 13, 5 (2016): 547-554.

3. Deogonda, Patil, and Vijaykumar N. Chalwa. "Mechanical property of glass fibre reinforcement epoxy composites." IJSER 1,4 (2013): 2347-3878.

4. Mohammed, Layth, MOHAMED NM Ansari, Grace Pua, Mohammad Jawaid, and M. Saiful Islam. "A review on natural fibre reinforced polymer composite and its applications." Int. J. Polym. Sci. 2015 (2015).

5. Joshi, Satish V., L. T. Drzal, A. K. Mohanty, and S. Arora. "Are natural fibre composites environmentally superior to glass fibre reinforced composites?." Compos. Pt. A-Appl. Sci. Manuf. 35,3 (2004): 371-376.

6. Arib, R. M. N., S. M. Sapuan, M. M. H. M. Ahmad, M. T. Paridah, and HMD Khairul Zaman. "Mechanical properties of pineapple leaf fibre reinforced polypropylene composites." Mater. Des 27, 5 (2006): 391-396.

7. Devi, L. Uma, S. S. Bhagawan, and Sabu Thomas. "Mechanical properties of pineapple leaf fibrereinforced polyester composites." J. Appl. Polym. Sci 64, 9 (1997): 1739-1748.

8. George, Jayamol, S. S. Bhagawan, N. Prabhakaran, and Sabu Thomas. "Short pineapple-leaf-fibrereinforced low-density polyethylene composites. " J. Appl. Polym. Sci 57, 7 (1995): 843-854.

9. George, Jayamol, S. S. Bhagawan, and Sabu Thomas. "Effects of environment on the properties of low-density polyethylene composites reinforced with 
pineapple-leaf fibre." Compos. Sci. Technol. 58, 9 (1998): 1471-1485.

10. Pavithran, C., P. S. Mukherjee, M. Brahmakumar, and A. D. Damodaran. "Impact properties of natural fibre composites." J. Mater. Sci. Lett. 6, 8 (1987): 882-884.

11. Mishra, S., A. K. Mohanty, L. T. Drzal, M. Misra, S. Parija, S. K. Nayak, and S. S. Tripathy. "Studies on mechanical performance of biofibre/glass reinforced polyester hybrid composites." Compos. Sci. Technol. 63, 10 (2003): 1377-1385.
12. John, Maya Jacob, and Rajesh D. Anandjiwala. "Recent developments in chemical modification and characterization of natural fibre-reinforced composites." Polym. Compos. 29, 2 (2008): 187-207.

13. ASTM International. ASTM D3039/D3039M-14 Standard Test Method for Tensile Properties of Polymer Matrix Composite Materials. West Conshohocken, PA: ASTM International (2014).

14. ASTM International. ASTM D7264/D7264M-15 Standard Test Method for Flexural Properties of Polymer Matrix Composite Materials. West Conshohocken, PA: ASTM International (2015). 